\title{
Genes differentially expressed in the peripheral zone compared to the transitional zone of the normal human prostate and their potential regulation by ETS factors
}

\author{
DAVID ADLER $^{1}$, ANDREAS LINDSTROT ${ }^{1}$, JÖRG ELLINGER ${ }^{2}$, \\ SEBASTIAN ROGENHOFER $^{2}$, REINHARD BUETTNER ${ }^{1}$ and NICOLAS WERNERT ${ }^{1}$ \\ ${ }^{1}$ Institute of Pathology; ${ }^{2}$ Department of Urology, University Hospital Bonn, D-53127 Bonn, Germany
}

Received May 19, 2011; Accepted September 13, 2011

DOI: $10.3892 / \mathrm{mmr} .2011 .628$

\begin{abstract}
Prostate cancer (PCa) is a clinically heterogeneous and multifocal disease with a clinical outcome that is difficult to predict. Notably, predisposition to develop prostate cancer is different among the prostate zones, with the peripheral zone (PZ) or prostate proper as the most frequent site compared to the transitional zone (TZ). Translocations between the TMPRSS2 gene and a number of members of the ETS family are frequently found in PCa. Here, we examined expression differences among the two zones by laser microdissection of normal tissues from PCa patients to separate glands from stroma, and investigated the gene expression differences in the glands of the PZ compared to those of the TZ using microarray analysis. We identified 9 genes involved in the so-called metastatic cascade, to be highly differentially expressed in the normal glands of the PZ compared to those of the TZ. The genes which were found to be up-regulated in the PZ compared to the $\mathrm{TZ}$ are commonly up-regulated in tumors. These findings may explain the lower susceptibility for $\mathrm{PCa}$ of the TZ compared to the PZ. According to bioinformatic analysis, $8 / 9$ of these genes may be potentially regulated by ETS transcription factors.
\end{abstract}

\section{Introduction}

As a leading cause of cancer mortality, prostate cancer (PCa) is a clinically heterogeneous and often multifocal disease with a clinical outcome that is difficult to predict (1-4). Therefore, knowledge about the molecular basis of PCa may improve the prediction of prognosis, as genetic aberrations have been reported to drive the formation and aggressiveness of the disease (5).

Correspondence to: Professor Nicolas Wernert, Institute of Pathology, University Hospital Bonn, Sigmund Freud Str. 25, D-53127 Bonn, Germany

E-mail: nicolas.wernert@ukb.uni-bonn.de

Key words: stroma, glands, ETS factors, prostate
According to McNeal (6) and Joshua et al (7), the prostate consists of three anatomical glandular zones that are supported by a stroma: the peripheral (the so-called prostate proper), the transitional and the central zone $(6,7)$. Notably, predisposition to develop $\mathrm{PCa}$ is different among these zones, with the majority of cases of cancer $(75 \%)$ occurring in the peripheral zone (PZ), compared to only $20 \%$ in the transitional zone (TZ) $(8,9)$, although the two zones show no histomorphological differences (6). Cancers originating from the PZ tend to be more aggressive and invasive compared to the cancers originating from the TZ, which are mostly non-aggressive $(8,10)$. Although embryological bases have been suggested to perhaps contribute to the difference in susceptibility among the prostate zones (11), the molecular reasons that lie behind such differences in susceptibility for PCa in PZ compared to the $\mathrm{TZ}$ remain to be unraveled.

Current molecular models suggest that high-grade prostatic intra-epithelial neoplasia (HGPIN) is likely to represent a precursor of $\mathrm{PCa}$ (7). The relatively recent discovery in the last decade of the ETS family gene fusions in PCa has been a major step towards understanding the molecular basis of the disease (7). Translocations between the TMPRSS2 gene, encoding an androgen-regulated prostate-specific serine protease, with a number of ETS family members, most commonly ERG, are frequently found in PCa $(1,12-14)$. It has been reported that the TMPRSS2-ERG fusions account for $50-80 \%$ of PCa occurrences (7). As a result of these translocations, the expression of the rearranged ETS factors are increased in response to androgens (12). Furthermore, ETS factors are known to play significant roles in the various steps of the so-called metastatic cascade (proliferation, apoptosis, migration, invasion and angiogenesis) in different tissues (12,15-20).

A previous study reported that there are gene expression differences between the $\mathrm{PZ}$ and the $\mathrm{TZ}$ of the prostate (21). However, laser microdisection has not yet been used to separately analyze the stromal cells and the normal glands. In the present study, we examined gene expression differences among the two zones by laser microdissection of epithelial from stroma cells, and then investigated expression differences specifically in the glands of the PZ compared to those of the TZ using microarray analysis. We report the identification of 9 genes which are involved in the so-called metastatic cascade, 
and which were found to be highly differentially expressed in the normal glands of the PZ compared to those of the $\mathrm{TZ}$ of the human prostate. Genes that were found to be up-regulated in the PZ compared to the $\mathrm{TZ}$ are commonly up-regulated in tumors, which may explain the differences of the prostate zones in susceptibility for $\mathrm{PCa}$. We further report the potential regulation of these genes by ETS factors.

\section{Materials and methods}

This study has been approved by the Faculty of Medicine's Ethics Review Board of the University of Bonn/University Hospital, Germany, according to the principles expressed in the Declaration of Helsinki. Written informed consents were obtained from all participants involved in the study. All the raw microarray data used in this study have been deposited in a MIAME compliant database, GEO. The accession number for the manuscript is GSE29090.

Processing of human prostatectomy specimens. Radical prostatectomy specimens were obtained from $\mathrm{PCa}$ patients immediately following surgery. The patients were not exposed to any treatment prior to surgery. Fresh tissue samples $(0.5 \times 0.5 \times 0.3 \mathrm{~cm})$ were obtained from the PZs (prostate proper) and the TZs of 20 prostate cancer patients, and shockfrozen in liquid nitrogen with ice-cold isopentane. Frozen sections $(6 \mu \mathrm{m})$ were cut from the samples using a cryotome (Leica, Germany) and mounted on membrane-coated slides (MembraneSlides, $1 \mathrm{~mm}$ PEN; Zeiss, Germany) for subsequent laser microdissection. One section was mounted on conventional slides and stained with hematoxylin and eosin (H\&E) for diagnostic evaluation by an experienced pathologist who confirmed the absence of prostate carcinoma in the two zones. Laser microdissection was performed as previously described (22-24). Frozen sections were dried for $2 \mathrm{~min}$ in the cryotome, washed for 2 min with $70 \%$ ethanol in DEPC-treated water and stained for $30 \mathrm{sec}$ in $1 \%$ cresyl violet diluted in $50 \%$ ethanol-DEPC-treated water. Slides were then washed briefly in 70 and $100 \%$ ethanol, dried for $10 \mathrm{~min}$ and stored at $-80^{\circ} \mathrm{C}$ until use for laser microdissection of normal glands and the stroma between them.

Quality control. The quality of the RNA was measured for every patient prior to laser microdissection using the Lasercapture Microscope (LCM). The section was washed from the slide with $600 \mu \mathrm{l}$ buffer RLT $+2 \mu \mathrm{M}$ DTT (provided by the RNeasy Mini kit; Qiagen, Germany) and vortexed for $30 \mathrm{sec}$. Then RNA-extraction was performed as described by the manufacturer. The recommended DNase digestion was made with an RNase-Free DNase Set (Qiagen). The quality of the RNA was measured with the Agilent Bioanalyzer 2100 (Agilent Technologies, Santa Clara, CA, USA). Samples with a RIN factor $>6$ were used for LCM.

Laser-capture microscopy. The cresyl violet-stained sections were cut with an Axio Observer.Z1 Microscope (Zeiss) and installed Palm MicroBeam (Zeiss). The LCM was performed under a x10 objective. The glands and the stroma of the PZs and the TZs were separated, and collected in $200 \mu \mathrm{l}$ AdhesiveCap tubes (Zeiss).
Microarray analysis of RNA isolated from laser microdissected healthy glands of the PZ and TZ of the prostate. RNA was isolated from laser microdissected healthy glands of the PZs and TZs of the prostate from the patients using the RNeasy Micro kit (Qiagen) as described by the manufacturer. The recommended DNase digestion is included with the RNase-Free DNase Set. The amount of the isolated RNA was measured with the Nanodrop photometer (Thermo Fisher Scientific, USA). Thereafter, an equal amount of RNA from the glands of healthy PZ and TZ of 10 patients each was pooled, respectively, to a final concentration of $300 \mathrm{ng}$ of RNA. These pools were sent to Miltenyi Biotec (Bergisch Gladbach, Germany) for the microarray analysis and bioinformatical interpretation. The RNA was labeled with $\mathrm{Cy} 3$ and hybridized on the Whole Human Genome Oligo Microarray 4x44K (Agilent, USA) according to the manufacturer's instructions. The microarray results were then validated by qRT-PCR of a subset of genes.

Transcription factor search. Search for ETS transcription factor binding sites within the promoter regions of the genes was performed using the Transcription Factor Search (TFSEARCH) $(25,26)$. The promoter retrieval of each gene was performed using the TRED database (27), followed by insertion into the TFSEARCH database $(25,26)$.

\section{Results}

Genes differentially expressed in normal glands of the PZ compared to the $T Z$ of the prostate. Using Whole Human Genome Oligo Microarray, genes differentially expressed in normal glands of the TZ compared to the PZ of the prostate were identified (data not shown). Clustering analysis based on gene function placed each gene into various categories, and the genes that were placed into the steps of the so-called metastatic cascade (proliferation, migration and angiogenesis) and the extracellular matrix category (which is related to invasion) were examined. A total of 351 genes were identified in the previously described four categories (data not shown). However, only genes which were found to be highly differentially expressed $(>10$-fold increase or decrease and $\mathrm{p}<0.01)$ in the PZ compared to the $\mathrm{TZ}$ of the prostate were considered significant (Tables I-V). The genes that were found to fulfill these conditions include MFAP5, ASPN, REGIA, KRAS, REG1B, F7, PKHDI, RUNXI and NOS1 (Tables I-V).

Genes with ETS transcription factor binding sites within promoter regions. A search for ETS transcription factor binding sites within the promoter regions of the 9 genes using TFSEARCH revealed that 8 of these genes have potential binding sites for ETS transcription factors (Table V).

\section{Discussion}

In the present study, gene expression differences between the normal glands of the $\mathrm{PZ}$ compared to those of the $\mathrm{TZ}$ of the human prostate were examined using microarray analysis. Due to the limited amounts of RNA that can be obtained from PCa tissues, RNA samples from individual patients had to be pooled to obtain enough RNA for microarray analysis. Genes 
Table I. Genes involved in proliferation.

\begin{tabular}{|c|c|c|}
\hline Gene & Name & Fold change \\
\hline REG1A & $\begin{array}{l}\text { Regenerating islet-derived } 1 \alpha \text {; } \\
\text { regenerating islet-derived } 1 \beta\end{array}$ & 87.7 \\
\hline$K R A S$ & $\begin{array}{l}\text { v-Ki-ras2; Kirsten rat sarcoma } \\
\text { viral oncogene homolog }\end{array}$ & 39.0 \\
\hline$R E G 1 B$ & $\begin{array}{l}\text { Regenerating islet-derived } 1 \beta \\
\text { regenerating islet-derived } 1 \alpha\end{array}$ & 19.4 \\
\hline \multicolumn{3}{|c|}{$\begin{array}{l}\text { The genes shown are up-regulated }>10 \text {-fold }(\mathrm{p}<0.01) \text { in the normal } \\
\text { glands of the } \mathrm{PZ} \text { compared to those of the } \mathrm{TZ} \text { of the human prostate. }\end{array}$} \\
\hline \multicolumn{3}{|c|}{ Table II. Genes involved in migration. } \\
\hline Gene & Name & Fold change \\
\hline$F 7$ & $\begin{array}{l}\text { Coagulation factor VII (serum } \\
\text { prothrombin conversion accelerator) }\end{array}$ & 17.3 \\
\hline PKHD1 & $\begin{array}{l}\text { Polycystic kidney and hepatic } \\
\text { disease } 1 \text { (autosomal recessive) }\end{array}$ & 14.2 \\
\hline
\end{tabular}

The genes shown are up-regulated $>10$-fold $(\mathrm{p}<0.01)$ in the normal glands of the PZ compared to those of the TZ of the human prostate.

Table III. Genes involved in angiogenesis.

\begin{tabular}{llc}
\hline Gene & \multicolumn{1}{c}{ Name } & Fold change \\
\hline RUNX1 & Runt-related transcription factor 1 & 100.0 \\
NOS1 & Nitric oxide synthase 1 & 32.8 \\
\hline
\end{tabular}

The genes shown are up-regulated $>10$-fold $(p<0.01)$ in the normal glands of the $\mathrm{PZ}$ compared to those of the $\mathrm{TZ}$ of the human prostate.

Table IV. Genes encoding components of the extracellular matrix.

\begin{tabular}{llc}
\hline Gene & \multicolumn{1}{c}{ Long name } & Fold change \\
\hline MFAP5 & Microfibrillar associated protein 5 & 16.4 \\
ASPN & Asporin & 13.1 \\
\hline
\end{tabular}

The genes shown are up-regulated $>10$-fold $(\mathrm{p}<0.01)$ in the normal glands of the PZ compared to those of the $\mathrm{TZ}$ of the human prostate.

that may be significantly affected among the patients rather than in an individual patient will remain significant in the pool.

A clustering analysis based on gene function placed each gene into various categories, and genes that were placed into the steps of the so-called metastatic cascade (proliferation, migration and angiogenesis) and the extracellular matrix category were examined. Out of 351 genes identified, only 9 were found to be highly differentially expressed ( $>10$-fold
Table V. ETS binding sites.

\begin{tabular}{lc}
\hline Gene & $\begin{array}{c}\text { No. of potential } \\
\text { ETS binding sites }\end{array}$ \\
\hline ASPN & 3 \\
$F 7$ & 1 \\
KRAS & 2 \\
MFAP5 & 3 \\
NOS1 & 5 \\
PKHD1 & 5 \\
REG1B & 1 \\
RUNX1 & 6 \\
\end{tabular}

The genes shown are the ones with potential ETS transcription factor binding sites within their promoter regions.

increase or decrease and $\mathrm{p}<0.01)$ in the $\mathrm{PZ}$ compared to the $\mathrm{TZ}$ in these categories (Tables I-V).

Proliferation. The genes REG1A, KRAS and REG1B were found to be $>10$-fold up-regulated in the normal glands of the PZ compared to those of the TZ (Table I).

Briefly, the growth factor REGIA has been reported to be highly expressed within breast carcinomas and is suggested to be an independent predictor of poor prognosis (28). It has also been found to be up-regulated in colon carcinoma patients with unfavorable clinical outcomes (29). Furthermore, overexpression of REG IA protein in PCa cell lines has been shown to lead to accelerated cell proliferation and tumor growth in vitro and in vivo (30). Activation of oncogenic KRAS is frequently found in pancreatic ductal adenocarcinoma (PDAC), and has been recently suggested to contribute to PDAC initiation (31). Furthermore, KRAS activation is suggested to be a founder event in melanomagenesis (32). Lastly, REG1B along with the above-mentioned $R E G 1 A$ is reported to be up-regulated during colorectal carcinogenesis (33). Analysis for potential ETS factors binding sites within the promoter regions of these genes revealed that KRAS and REGIB have 2 and 6 potential ETS factor binding sites, respectively (Table V).

Migration. F7 and PKHDl were found to be $>10$-fold up-regulated in the normal glands of the PZ compared to those of the TZ (Table II). Briefly, it has been reported that colorectal cancer is capable of ectopically synthesizing F7 (fVII), and a microenvironment with a high F7 protein could lead to promoting tumor metastasis (34). Furthermore, ectopic F7 expression is frequently reported in ovarian cancers as well (35). Finally, the protein polyductin, encoded by the PKHDl gene, was detected in cholangiocellular carcinoma (36). One potential ETS factor binding site was found within the promoter regions of $F 7$ as well as of PKHDl (Table V).

Angiogenesis. The genes RUNX1 and NOS1 were found to be $>10$-fold up-regulated in the normal glands of the PZ compared to those of the TZ (Table III). Briefly, RUNX1, which was found to be expressed 100-fold more in the PZ compared to the $\mathrm{TZ}$, is reported to be expressed in PCa cell lines as well and 
suggested to cooperate with the ETS transcription factor PDEF in regulating the expression of the prostate-specific antigen (PSA) (37). NOS1 expression is reported to be associated with decreased survival rates in patients with chondrosarcoma (38). Lastly, 4 and 5 potential ETS factor binding sites within the promoter regions of RUNX1 and NOS1 were found, respectively (Table V).

Extracellular matrix. The genes MFAP5 and ASPN were found to be $>10$-fold up-regulated in the normal glands of the PZ compared to those of the TZ (Table IV). MFAP5, also known as $M A G P 2$, has been suggested to serve as a signature in advanced ovarian cancer and to promote tumor cell survival and angiogenesis (39). ASPN has been reported to be highly up-regulated in lobular carcinomas of the breast compared to normal ductal epithelium (40). Analysis for potential ETS factor binding sites within the promoter regions of these genes revealed three potential sites in MFAP5 and ASPN (Table V).

Taken together, we identified 9 highly differentially expressed genes in the normal glands of the PZ compared to the $\mathrm{TZ}$ of the human prostate. The genes which were found to be up-regulated in the PZ compared to the $\mathrm{TZ}$ are up-regulated in various types of cancer, which may explain the differences in susceptibility for PCa of the TZ compared to the PZ. Eight out of 9 of these genes may be potentially regulated by ETS transcription factors, which is suggested by the presence of ETS factor binding sites in the promoters of these genes. Our assumption is further supported by our own findings showing that ETS factors are expressed more in the normal glands of the PZ compared to those of the TZ (unpublished data). Furthermore, ETS members have been reported to be involved in tumor angiogenesis, proliferation and invasion (41-44), and found to be overexpressed in latent and clinically manifest prostatic carcinomas (45). Future studies should examine the role of these selected genes and their potential regulation by ETS-1 in prostate cell lines derived directly from the normal glands of the PZ, the $\mathrm{TZ}$ and of PCa.

\section{Acknowledgements}

The authors are grateful to the DFG (Deutsche Forschungsgemeinschaft; German Research Association, grant no. WE 1104/11-1), and the German Cancer Aid (Deutsche Krebshilfe, grant no. 107827) for the financial support.

\section{References}

1. Kumar-Sinha C, Tomlins SA and Chinnaiyan AM: Recurrent gene fusions in prostate cancer. Nat Rev 8: 497-511, 2008

2. Richardson AM, Woodson K, Wang Y, et al: Global expression analysis of prostate cancer-associated stroma and epithelia. Diagn Mol Pathol 16: 189-197, 2007.

3. Arora R, Koch MO, Eble JN, Ulbright TM, Li L and Cheng L: Heterogeneity of Gleason grade in multifocal adenocarcinoma of the prostate. Cancer 100: 2362-2366, 2004.

4. Ruijter ET, van de Kaa CA, Schalken JA, Debruyne FM and Ruiter DJ: Histological grade heterogeneity in multifocal prostate cancer. Biological and clinical implications. J Pathol 180: 295-299, 1996.

5. DeMarzo AM, Nelson WG, Isaacs WB and Epstein JI: Pathological and molecular aspects of prostate cancer. Lancet 361: 955-964, 2003.

6. McNeal JE: The zonal anatomy of the prostate. Prostate 2: 35-49, 1981.
7. Joshua AM, Evans A, van der Kwast T, et al: Prostatic preneoplasia and beyond. Biochim Biophys Acta 1785: 156-181, 2008.

8. McNeal JE, Redwine EA, Freiha FS and Stamey TA: Zonal distribution of prostatic adenocarcinoma. Correlation with histologic pattern and direction of spread. Am J Surg Pathol 12: 897-906, 1988.

9. Guo CC, Zuo G, Cao D, Troncoso P and Czerniak BA: Prostate cancer of transition zone origin lacks TMPRSS2-ERG gene fusion. Mod Pathol 22: 866-871, 2009.

10. Colombo P, Patriarca C, Alfano RM, et al: Molecular disorders in transitional vs. peripheral zone prostate adenocarcinoma. Int J Cancer 94: 383-389, 2001.

11. Laczko I, Hudson DL, Freeman A, Feneley MR and Masters JR: Comparison of the zones of the human prostate with the seminal vesicle: morphology, immunohistochemistry, and cell kinetics. Prostate 62: 260-266, 2005.

12. He J, Pan Y, Hu J, Albarracin C, Wu Y and Dai JL: Profile of Ets gene expression in human breast carcinoma. Cancer Biol Ther 6: 76-82, 2007.

13. Tomlins SA, Rhodes DR, Perner S, et al: Recurrent fusion of TMPRSS2 and ETS transcription factor genes in prostate cancer. Science 310: 644-648, 2005.

14. Furusato B, Tan SH, Young D, et al: ERG oncoprotein expression in prostate cancer: clonal progression of ERG-positive tumor cells and potential for ERG-based stratification. Prostate Cancer Prostatic Dis 13: 228-237, 2010.

15. Kohn EC: Invasion and metastasis: biology and clinical potential Pharmacol Ther 52: 235-244, 1991.

16. Duffy MJ, McGowan PM and Gallagher WM: Cancer invasion and metastasis: changing views. J Pathol 214: 283-293, 2008.

17. Oikawa T: ETS transcription factors: possible targets for cancer therapy. Cancer Sci 95: 626-633, 2004.

18. Hashiya N, Jo N, Aoki M, et al: In vivo evidence of angiogenesis induced by transcription factor Ets-1: Ets-1 is located upstream of angiogenesis cascade. Circulation 109: 3035-3041, 2004.

19. Rothhammer T, Hahne JC, Florin A, et al: The Ets-1 transcription factor is involved in the development and invasion of malignant melanoma. Cell Mol Life Sci 61: 118-128, 2004.

20. Hahne JC, Okuducu AF, Kaminski A, Florin A, Soncin F and Wernert N: Ets-1 expression promotes epithelial cell transformation by inducing migration, invasion and anchorage-independent growth. Oncogene 24: 5384-5388, 2005.

21. Van der Heul-Nieuwenhuijsen L, Hendriksen PJ, van der Kwast TH and Jenster G: Gene expression profiling of the human prostate zones. BJU Int 98: 886-897, 2006.

22. Wellmann A, Wollscheid V, Lu H, et al: Analysis of microdissected prostate tissue with ProteinChip arrays - a way to new insights into carcinogenesis and to diagnostic tools. Int J Mol Med 9: 341-347, 2002.

23. Okuducu AF, Janzen V, Hahne JC, Ko Y and Wernert N: Influence of histochemical stains on quantitative gene expression analysis after laser-assisted microdissection. Int J Mol Med 11: 449-453, 2003.

24. Okuducu AF, Hahne JC, von Deimling A and Wernert N: Laser-assisted microdissection, techniques and applications in pathology (Review). Int J Mol Med 15: 763-769, 2005.

25. Akiyama Y: TFSEARCH: Searching Transcription Factor Binding Sites, 2011. Available from URL: http://mbs.cbrc.jp/ research/db/TFSEARCHJ.html.

26. Heinemeyer T, Wingender E, Reuter I, et al: Databases on transcriptional regulation: TRANSFAC, TRRD and COMPEL. Nucleic Acids Res 26: 362-367, 1998.

27. Laboratory CSH: Transcriptional Regulatory Element Database, 2011.

28. Sasaki Y, Minamiya Y, Takahashi N, et al: REG1A expression is an independent factor predictive of poor prognosis in patients with breast cancer. Ann Surg Oncol 15: 3244-3251, 2008.

29. Astrosini C, Roeefzaad C, Dai YY, Dieckgraefe BK, Jons T and Kemmner W: REG1A expression is a prognostic marker in colorectal cancer and associated with peritoneal carcinomatosis. Int J Cancer 123: 409-413, 2008.

30. Zhou L, Zhang R, Wang L, et al: Upregulation of REG Ialpha accelerates tumor progression in pancreatic cancer with diabetes. Int J Cancer 127: 1795-1803, 2010.

31. Lee KE and Bar-Sagi D: Oncogenic KRas suppresses inflammation-associated senescence of pancreatic ductal cells. Cancer Cell 18: 448-458, 2010.

32. Milagre C, Dhomen N, Geyer FC, et al: A mouse model of melanoma driven by oncogenic KRAS. Cancer Res 70: 5549-5557, 2010. 
33. Rechreche H, Montalto G, Mallo GV, et al: pap, reg Ialpha and reg Ibeta mRNAs are concomitantly up-regulated during human colorectal carcinogenesis. Int J Cancer 81: 688-694, 1999.

34. Tang JQ, Fan Q, Wan YL, et al: [Ectopic expression and clinical significance of tissue factor/coagulation factor VII complex in colorectal cancer]. Beijing Da Xue Xue Bao. 41: 531-536, 2009 (In Chinese)

35. Yokota N, Koizume S, Miyagi E, et al: Self-production of tissue factor-coagulation factor VII complex by ovarian cancer cells. $\mathrm{Br}$ J Cancer 101: 2023-2029, 2009.

36. Dorn L, Menezes LF, Mikuz G, Otto HF, Onuchic LF and Sergi C: Immunohistochemical detection of polyductin and co-localization with liver progenitor cell markers during normal and abnormal development of the intrahepatic biliary system and in adult hepatobiliary carcinomas. J Cell Mol Med 13: 1279-1290, 2009.

37. Fowler M, Borazanci E, McGhee L, et al: RUNX1 (AML-1) and RUNX2 (AML-3) cooperate with prostate-derived Ets factor to activate transcription from the PSA upstream regulatory region. J Cell Biochem 97: 1-17, 2006.

38. Reid-Lombardo KM, Fridley BL, Cunningham JM, Sarr M and Petersen GM: Inflammation-related gene variants as risk factors for pancreatic cancer. Cancer Epidemiol Biomarkers Prev 20 : 1251-1254, 2011

39. Spivey KA and Banyard J: A prognostic gene signature in advanced ovarian cancer reveals a microfibril-associated protein (MAGP2) as a promoter of tumor cell survival and angiogenesis. Cell Adh Migr 4: 169-171, 2010.
40. Turashvili G, Bouchal J, Baumforth K, et al: Novel markers for differentiation of lobular and ductal invasive breast carcinomas by laser microdissection and microarray analysis. BMC Cancer 7: 55, 2007.

41. Behrens P, Rothe M, Wellmann A, Krischler J and Wernert N: The Ets-1 transcription factor is up-regulated together with MMP 1 and MMP 9 in the stroma of pre-invasive breast cancer. J Pathol 194: 43-50, 2001.

42. Behrens P, Mathiak M, Mangold E, et al: Stromal expression of invasion-promoting, matrix-degrading proteases MMP-1 and -9 and the Ets 1 transcription factor in HNPCC carcinomas and sporadic colorectal cancers. Int J Cancer 107: 183-188, 2003.

43. Wernert N, Stanjek A, Kiriakidis S, et al: Inhibition of angiogenesis in vivo by Ets-1 antisense oligonucleotides-inhibition of Ets-1 transcription factor expression by the antibiotic fumagillin. Angewandte Chemie 38: 3228-3231, 1999.

44. Wernert N, Gilles F, Fafeur V, et al: Stromal expression of c-Ets1 transcription factor correlates with tumor invasion. Cancer Res 54: 5683-5688, 1994.

45. Alipov G, Nakayama T, Ito M, et al: Overexpression of Ets-1 proto-oncogene in latent and clinical prostatic carcinomas. Histopathology 46: 202-208, 2005. 